\title{
公JO'厂E
}

African Journal of Teacher Education

ISSN 1916-7822. A Journal of Spread Corporation

Volume 10. No. 12021 Pages 195-221

\section{Maximizing Science Learning through Practical Work in Secondary Schools in Tanzania: Student-Teachers' Adaptation to Language Supportive Pedagogy}

\author{
Festo Nguru \\ The University of Dodoma, Tanzania
}

\begin{abstract}
There is a lack of clarity about the role of practical work in promoting learning and thinking, due to mediocrity in the way it is being handled. This study used mixed methods design to develop through microteaching, LSP integrated practical work to explore its characteristics in order to examine how the student-teachers adapted to the pedagogy in relation to its efficacy in developing science, English language, and pedagogy. The research was conducted at the University of Dodoma. The study involved 63 student-teachers and five lecturers with different specializations. The study was carried out in three cycles at the College of Education. It involved the second-year students who were studying Bachelor of Education in Science, who undertook a Physics Teaching Methods course. Review of lesson plans, achievement tests, classroom observations, and interviews with student-teachers, together with focus group discussions among the lecturers, were used to collect data. The qualitative data were analysed using the thematic analysis approach, while the quantitative data were analysed through repeated measures t-test. The student-teachers were able to plan and implement LSP practical lessons in which case students reported to have enjoyed their participation, sharing of experiences, and the bilingual classrooms. The findings from the repeated measures $t$-test show that there was a significant rise in the mean scores from pre-test (67.9) to the post-test (80.2), with very much reduced variability (SD) of scores among students from 24.9 (pre-test) to 6.6 (post-test). From interviews with 8 case students after each lesson, it was concluded that the students improved in science content, English language competence, and pedagogy.
\end{abstract}


Keywords: language supportive practical work; language supportive pedagogy; pre-service science teacher education; secondary science education; collaborative science teacher development

\section{Background to the Study}

\subsection{Introduction}

Many scientists and science educators acknowledge that practical work occupies the central place in science education. According to Millar (2004), practical work refers to any teaching and learning activity in which students are involved in observing or manipulating real objects and materials they are studying. Practical experiences are essential for understanding science. However, there is a debate on the efficacy of practical work in elementary education (Abrahams \& Millar, 2008; Hodson, 1998; Millar, Le Mare'chal \& Tiberghien, 1999; Watson, 2000). Generally, there is lack of clarity about the role of practical work in achieving educational aims. White (1996), in his study, made a conclusion that there was insufficient evidence that practical work promotes better understanding of the methods of science and abstraction processes, make information memorable, motivate and reveal links between topics. Abrahams and Millar (2008) claim that, the way practical work is administered cause a waste of time, particularly when students are engaged in practicing procedures of experiments, rather than learning concepts behind the phenomena. Jokiranta (2014) argues that, waste of time may occur when practical work uses the cook-book approach without engaging students in thinking. This controversy about practical works is due to mediocrity in the way practical tasks are being handled in various contexts by various stakeholders. Abrahams and Millar (2008) argue that, kinds of practical work conducted are effective only in making the students do what they are instructed to do with the physical objects. They are not effective for promoting effective learning and thinking. They also observed that, there was little evidence that teachers are aware of addressing the cognitive challenge of linking observables with the ideas in designing practical activities for science lessons. Thus, there is a need to improve effectiveness and efficiency of practical works.

Similarly, in Tanzania, in general, secondary school teachers have been reported as less motivated in involving practical works in teaching Physics. Kibga (2013) reported that, in Tanzania, there is a trend of poor practical experiences in secondary schools as well as in teacher education institutions. Even when the teachers engage their science students in experiments, 
practical and theoretical lessons are taught separately as two disconnected subjects (Kibga, 2013). This tendency is most likely to make students work on practical activities without much reflection on the actions, thus resulting in poor achievement and insufficient to development of critical thinking (Hinneh, 2017; Kim \& Chin 2011). It sometimes even confuses the students (Sharpe 2012).

This study used Language Supportive Pedagogy (LSP) in attempting to improve practical work in teaching science, making practical oriented lessons more efficient in the achievement of the educational goals and purposes of teaching science. Language Supportive Pedagogy (LSP) is a pedagogic approach that supports language within subjects other than English language. It is a kind of pedagogy that supports both science and language learning. It builds on social-cultural, sociolinguistic and constructivist theories of leaning. The research comprised of an intervention whereby designed practical-oriented science lessons integrated with language supportive pedagogy were developed through micro-teaching. The aim was to explore the characteristics and effectiveness by observing how student-teachers adapted to the intervention.

\subsection{Theoretical Framework}

According to Piaget (1973), learners construct knowledge through interaction with the social and cultural environment in which they live. Vygotsky (1978), emphasizes that, social interaction enhances construction of knowledge. Knowledge construction is consolidated when our ideas are accepted and or challenged by others where they differ. "Through social interaction, our ideas are modified and refined - and so are shaped towards a shared set that makes discourse and collaborative action possible." (Millar 2004, p.8). Therefore, practical work becomes more effective when it is associated with discussion about the observations, measurements, and the outcomes of the practical activity. So a typical practical activity will be followed by a period of discussion of the observations and measurements made, patterns in them (such as similarities, differences, correlations and trends), and how they might be interpreted and explained. (Millar, 2004, p.9). Therefore, in a practical oriented lesson, students are expected to share their ideas about what they are doing, and the findings they come up with.

Science is the use of theoretical models and data deriving from verifiable experiments or observation to study the material world around us. Making sense of the world involves using and developing language to communicate meaning (Exploratorium, 2015). Science uses language to 
communicate observations. Hence, science and language are inseparable. Science students are required to speak, listen, read and write about science.

De Oliveira, Obenchain, Kenney, Oliveira (2019) assert that recently there has been an advocacy for a shift of approach from learning language only in the language classroom, to language learning across e curriculum, whereby curriculum spaces are created in which language and content are integrated and coexist harmoniously across all school subjects. Pando and Aguirre-Muñoz (2019) argue that, in teaching science, we should consider the social practice of scientific communities in which language is used in conducting investigations, making sense of information gathered, and informing the scientific community. Therefore, teachers must provide their learners with science instruction that integrates both content concepts and language communication skills. Thus, appropriate learning and doing of science should support the development of language skills, as learning and doing science requires the use of language skills. Lunetta (1998) argues that practical task alone is not sufficient to enable students to construct the meaning for complex science concepts. According to Nomlomo \& Vuzo (2014), research conducted in many countries shows that teachers and students who are non-native speakers of English experience problems in the classroom that uses English as a language of instruction. The same experience has been reported to exist in Sub-Saharan Africa by Milligana, Clegg \& Tikly (2016). Generally, many African learners are disadvantaged educationally as they struggle to learn through English, the medium of instruction which is the foreign language (Nomlomo, 2007).

According to de Oliveira, Obenchain, Kenney and Oliveira (2019), content-language integrated practice involves visualizations, writing (text production), oral discussions and kinaesthetic activities; whereby physical activity can take a wide range of forms spanning from physical manipulation of tangible objects as part of science inquiries to stimulate thinking and discussions. Nutta et al. (2011) suggest a framework for creating effective environment for second language learning with five principles: The first principle is about providing the learners with many opportunities to read, write, listen and discuss oral and written English texts expressed in various ways. The second principle is drawing attention to patterns of English language structure. That is, while teaching the science subjects, teachers and students need to pay attention to the English language structure. The third principle requires that learners be given classroom time to practice their English productively. Moreover, while teaching, give the 
learners opportunities to notice their language errors and to correct them (The fourth principle). Finally, the fifth principle states that,construct activities that maximize opportunities for learners to interact with others in English. Nutta et al. (2011) emphasize that teachers and students should reflect on how they use English. Furthermore Zehler (1994) suggests some strategies that teachers can use to engage learners. These activities include asking more probing questions which require new or extended responses, creating opportunities for sustained dialogue and substantive language use, providing opportunities for language use in multiple settings, providing specific explanations of key words and special or technical vocabulary, and using everyday language.

\subsection{Literature Review}

Generally, science students, whose native language is not English, have limited language proficiency. Hence, it is difficult for them to comprehend the science concepts which are communicated through English Language as the language of instruction (Nutta, Bautista \& Butter, 2011). In such a context, learners normally face the challenge of accessing and constructing knowledge (Thomson, 2012). Secondary school students in Tanzania fit into the words of Nutta et al. (2011), who refer to such students as English Language Learners (ELLs) or Speakers of Other Languages. These still need to learn more English to succeed in learning science at school. The Tanzanian Educational and training policy stipulated the use of English as language of instruction in secondary schools. Due to poor English proficiency skills, students struggle to grasp the content of subjects taught through the English language, and this affects their academic performance adversely (Heugh, 2003). Learners' interaction is limited to participate in social and academic life in the classroom since each subject has its own specific language i.e. its own vocabulary and genres of writing. Therefore, teachers need to identify ways to support language development (Thomson, 2012). Mwinsheikhe (2009), conducted a study to investigate the teachers and students' English proficiency in secondary schools in Tanzania, focusing on science lessons. The author observed that there was deficiency in English competency among the students as well as teachers. Teachers reported to have been filling nervous in classroom they were supposed to use English only. Student participation was very minimal as majority of them could not express themselves clearly. Only, a small proportion of students could express in English freely. However, when working in groups the students 
preferred to use Kiswahili. Among the strategies the teachers used to handle this situation included code-switching and teaching English language in addition to the subject matter. Low language proficiency in English was reported to limit learning in secondary schools in Tanzania (Rubagumya, Afitsca, Clegg \& Kiliku , 2011). However, Qorro (2009) contends that while research findings show that the use of foreign language as a medium of instruction leads to low access of education; pressure from parents and policy makers prefer the use of English as language of instruction. Among the reasons they give is that in this error of globalization and free markets we need English to interact with the international world. Thus, currently, English is the language of instruction in secondary schools and higher education in Tanzania. The Tanzanian Education and Training Policy 2014 recommends the use of both Kiswahili and English as Languages of Instruction at all levels of Education and training, including secondary schools (URT, 2014). However, recently no guideline has been provided on the use of the languages of instruction. Hence, till now English is used as a language of instruction in secondary schools.

Milligana, Clegg \& Tikly (2016) conducted a mixed method exploratory research aiming at understanding the pre-existing status of learning in Primary 4 classrooms and the impact of the introduction of language supportive pedagogy training and textbooks, in Rwanda. The sample consisted of eight treatment and control schools. The study involved the use of language materials by trained teachers in the LSP. Findings had shown that teachers had positive attitude on the bilingual classrooms (Kinyarwanda and English in this case) in the textbooks through glossaries and speaking activities. The language supportive textbooks allowed learners and teachers to engage with the activities and read the simpler content for curriculum understanding and language development. The learner centered teaching that involved talking, writing and reading facilitated learning. The findings suggested that language supportive learning can lead to significant improvements in learner outcomes and more effective engagement with subjects across the curriculum.

Therefore, science learning needs to go together with language development. Recent research suggests that the integration of these seemingly disparate areas is advantageous to both (Exploratorium, 2015). However, pre-service teachers are rarely oriented to the integration of language learning in the learning of science (Cho \& McDonnough, 2009). Milligana, Clegg \& Tikly (2016) add that, in policy discussions in Sub-Saharan Africa it is rare to find language 
being discussed as an issue for all teachers teaching all the subjects to consider; instead is considered as the territory of the English teachers in the school to develop learners' language. Consequently, teachers do only prepare activities which help their students learn the subject matter. They rarely think about the language development potential that the same activities may breed. Although Mwinsheikhe (2009) puts and argument that not every teacher can teach English. It is the belief of this research that the science teachers may be trained to develop English proficiency skills, and while in the field they may be encouraged to collaborating with English teachers in their workings, and make significant contribution to the boosting students' English language proficiency.

\section{Purpose of the study}

This study aimed at exploring the characteristics of practical work integrated with language supportive pedagogy (LSP), and how student-teachers adapt the model in relation to science learning, language learning, and pedagogy. This was an attempt to design practical oriented lessons to increase learning efficiency among secondary schools students through microteaching. Therefore the study was guided by the following specific objectives:-

1) To investigate the characteristics of LSP integrated practical work in relation to learning of science, English language proficiency, and development of pedagogy; and

2) To evaluate the adaptation of the students-teachers to the LSP integrated practical work in relation to its efficiency to learning science, language proficiency, and development of pedagogy.

\section{Research Questions}

1) What are the characteristics of LSP integrated practical work in relation to science learning, English language proficiency development and development of pedagogy?

2) How did the student-teachers adapt to the LSP integrated practical work to enhance science learning, development of English language proficiency skills and pedagogy? 


\section{Research methods}

This study used mixed methods design. As the study was conducted in the natural setting involving pre and post-tests, it adopted a case study design which was complemented with pretest post-test a quasi-experimental research design. Yin (2018) defines case study as an empirical method that investigates phenomenon in depth within its natural (real-world) context, especially when the boundaries between the phenomenon and the context may not be clearly separated. Hence, the contextual conditions were relevant to this study. The research comprised of an intervention whereby designed practical-oriented science lessons integrated with language supportive pedagogy were developed through micro-teaching. The aim was to explore its characteristics and effectiveness and observing how student-teachers adapted the pedagogy. The data collection methods involved: pre and post tests for (63) student-teachers; observations and interviews to 8 purposefully selected students, four males and 4 females from high achievers and low achievers; and focused group discussions among lecturers specializing in areas under research, language, Physics, and education.

This study was carried out at the University of Dodoma, College of Education, in the year 2018 from February to June. The study used purposive sampling technique to obtain five lecturers and 63 students, and to select eight case students. The study involved five lecturers; three with specialization in science education from the College of Education, one with specialization in Physics from the College of Natural and Mathematical Sciences, and the another one with specialization in English Language from the College of Humanities and Social Sciences. Hence, the study involved multidisciplinary lecturers to enhance all the types of skills which were to be developed, i.e. pedagogy, content and English language. The study involved 63 second year students pursuing Bachelor of Education in Science, and Bachelor of Education in Science with ICT programmes, who undertook a course with code number SC 221 titled Physics Teaching Methods. Among the 63 students, 8 students were purposively sampled as case study students. The list of case study students list comprised of four high performing and four low performing students. The details of the characteristics of the case students are shown in the Table 3.1. Gender was greatly taken into account to obtain the proportionate representative sample, whereby two high performing male students and two high performing female students were involved in the study. 
Table 3.1: Characteristics of the Selected Case Students

\begin{tabular}{|c|c|c|c|c|c|c|c|c|}
\hline $\begin{array}{l}\text { Case } \\
\\
\begin{array}{l}\text { Stude } \\
\text { nt }\end{array}\end{array}$ & CS1 & CS2 & CS3 & CS4 & CS5 & CS6 & CS7 & CS8 \\
\hline Sex & $\mathrm{M}$ & $\mathrm{M}$ & $\mathrm{F}$ & $\mathrm{F}$ & $\mathrm{F}$ & $\mathrm{F}$ & $\mathrm{F}$ & $\mathrm{M}$ \\
\hline $\begin{array}{l}\text { Pre-test } \\
\qquad \begin{array}{l}\text { score } \\
/ 100\end{array}\end{array}$ & 39.5 & 53 & 69.5 & 77.5 & 81 & 85 & 89 & 91 \\
\hline $\begin{array}{c}\text { Performance } \\
\text { Statu } \\
\text { s }\end{array}$ & LP & LP & LP & LP & HP & HP & HP & HP \\
\hline
\end{tabular}

Key: CS - Case student, M - male, F- female, LP - low performing, HP - high performing

Source: Field Data (2018)

Similarly, two low performing male students and two low performing female students were also involved in the study. Review of lesson plans produced by the student-teachers, classroom observations, focus group discussions by the lecturers and interviews to the case students were used to explore the characteristics for the model and student-teachers adaptation to it. Achievement tests were used to determine the changes brought about by the model in relation to science learning, and development of English language and pedagogy.

\section{The Research Process}

Prior to the implementation of the lessons a pre-test on Physics Teaching Methods course was undertaken by all students to establish learning status of the student-teachers and to select the case students. The test was jointly prepared by the lectures in a focus group discussion. The test was composed of 114 multiple choice items on the key vocabulary rerated to physics content in secondary schools, and physics education. Excerpts for marked script for question number 17 and 38 are shown in Figure 3.1 
Figure 3. 1: Excerpts from the Marked Test Items for Questions 17 \& 38 for Pre-test (Field Data, 2018)
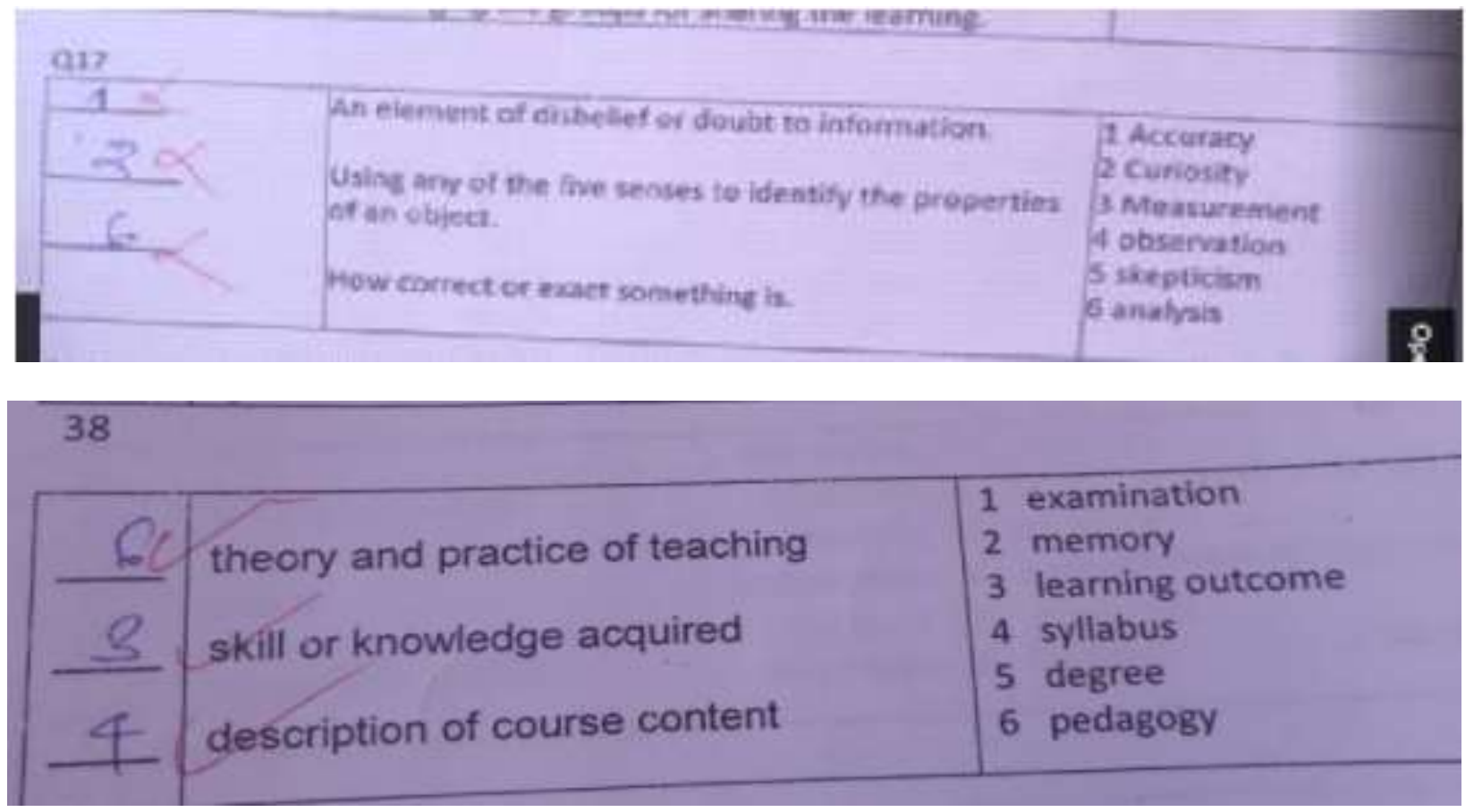

There were also a few descriptive questions which could determine competencies related to English language and physics pedagogy. The descriptive questions included tasks related to state 5 methods used in teaching physics, and select one he/she considered the best and give reasons. In another task the student-teachers were given extracts of the topic of refraction from two textbooks. The student-teachers were supposed to use four reasons in selecting one text extract which was better for teaching Form Two secondary school students. The test was prepared and marked by all the five lectures ensure high reliability and validity. For the internal consistence of the items pre-test the Cronbach's alpha reliability was determined to be 0.813 which is high.

Three cycles of lessons were implemented and evaluated, the first cycle spent four hours and the other two cycles spent 2 hours each. The topics for study were chosen from the course outline. The topic for the first lesson was content number 4 which was about Laboratory Techniques and Management. Section 4.2 was picked which was about Designing and carrying out practical works (experiments) relevant with the Tanzanian ordinary secondary school 
curriculum. The content for the second and third lessons was selected from module three. It was about approaches in teaching and learning Physics. Section number 3.3 of the content required the students to make classroom presentations (microteaching) of some Physics topics from the secondary school syllabus. While the first lesson cycle was taken up by a lecturer, the $2^{\text {nd }}$ and $3^{\text {rd }}$ cycles required student-teachers in groups of five to prepare practical oriented language supportive lessons and presented in classroom for about 60 minutes. Therefore, there were two lessons in each cycle. There were three types of objectives in the lessons: content objectives, English language learning objectives and pedagogy development objectives. The lessons objectives for the first cycle included:

Content Objectives: By the end of the cycle a student teachers was expected to be able to:-

1) compare and contrast practical work, experiment and investigation;

2) discuss the features of an experimental design;

3) explaining experimental procedures;

4) perform experiments relevant with the Tanzanian ordinary secondary school curriculum;

5) write experimental reports.

Pedagogical objectives: By the end of the cycle a student-teacher was expected to be able to:-

(1) Plan language supportive practical oriented lessons;

(2) Distinguish practical work, experiment and investigation;

(3) Explaining experimental procedures;

(4) Design, perform and supervise experiments for students in secondary schools;

(5) Perform experiments for demonstration;

(6) Write experimental report with both scientific format and language qualities;and

(7) Evaluate experimental reports written by students.

English language development objectives: By the end of the cycle a student-teacher was expected to be able to:- 
1) Use the vocabulary related to the key terms used in the topic / subtopic experimental design, procedures and report;

2) Develop reading skills using science based practical work texts.

3) Use of simple-present-tense in designing experiments;

4) Use of past tense in reporting experiments;

5) Use of passive voice in reporting experiments; and

6) Write experimental reports using the scientific format using appropriate language.

The lessons were prepared jointly among the lecturers. The first lesson on laboratory techniques was executed by one lecturer while being observed by the other four lecturers. The four observers filled in a special checklist as the lesson went on. Each of the lesson observers was also assigned to give the lesson feedback at the end of each lesson. In the first lesson, three tasks were administered to student-teachers. The first task, students using think pair share discussed the contrast among practical work, experiments and investigations. For the second task the teacher, through jigsaw method guided the students in groups of five to discuss the features of experimental design: title of the experiment, purpose of the experiments and procedures were discussed. In the second lesson of the first cycle, student-teachers in groups of five were given experimental design to read and follow the steps of performing an experiment to determine acceleration due to gravity at $\mathrm{Ng}$ 'hong'hona village, where the College of Education is situated. While doing the experiment the teachers passed from one group to another to ask the students questions about the aim of the experiment, the apparatus used, procedures they followed and the results they obtained. By the end of the session the teacher through plenary discussion asked the students to share their findings on the acceleration due to gravity at $\mathrm{Ng}$ 'hong'hona. Finally, the students were instructed to write a report of the experiment, as homework, answering the questions about what they did, why they did it (purpose / aim of the experiment), how they did it (Experimental procedures or methodology), what results they obtained (Experimental results or data), what did the data tell (Data analysis and discussion of results) and What they thought was the significance of the results (conclusion).

The objectives for the second and third cycles were as follows: 
Science Learning Objectives: By the end of the cycles a student was expected to be able

1) to identify the features of LSP integrated practical lesson;

2) to plan an LSP integrated practical lesson; and

3) to implement an LSP oriented practical lesson.

Language Learning Objectives: By the end of the cycles a student was expected to be able to:-

1) Use the vocabulary related to the key terms related to the topic;

2) Use the vocabulary related to the apparatus used in the practical works;

3) Explain the procedures for doing practical works;

4) Explain the observations from the practical activities;

5) Report the findings from the practical activities; and

6) Draw conclusions and deduce theories from the practical works.

Pedagogical Objectives: By the end of the cycle a student was expected to be able to:-

1) Plan an LSP integrated practical lesson;

2) Implement and LSP integrated practical lesson; and

3) Evaluate an LSP integrated practical lesson.

The second cycle was composed of two lesson presentations from the students. The content was extracted from the third course content which was about approaches in teaching and learning Physics. The student teachers in groups of five were supposed to prepare language supportive practical oriented lessons which were presented in 60 minutes each (in two days). The first lesson presented by student-teachers was about pressure in liquids. The content objectives for the lesson were firstly to determine the factors affecting liquid pressure; secondly, was to be able to derive the formula for determining amount of pressure exerted by liquids in specific contexts, thirdly to explain the applications of liquid pressure in daily life. The language objectives included to comprehend the key vocabulary related to pressure in liquids such as pressure, depth, altitude, water jets, bottom and top. Another language objective was describing appropriately the relationship between depth / altitude and density and liquid pressure. E.g. 
Liquid pressure depends on density. Pressure in liquids depends on depth. Pressure in a liquid is directly proportional to the depth below the surface. In the first task the student teachers guided the students to determine the effect of depth in liquids using practical activities. For the second task the student-teacher guided the students step by step to derive the formula for determination of liquid pressure through writing in their exercise books. The third task required the students to discuss the applications of pressure in liquids. The second presentation was about Transformer. The content objectives for the lesson included (i) to explain the structure and mode of action of a transformer; (ii) to determine the transformer equation; and (iii) to explain the uses of transformers. The language objectives included comprehending the key terms related to the topic, like transformer, coil, voltage, secondary coil, primary coil, secondary voltage, primary voltage, step-up, step-down, power, efficiency, welding, and laminate. The second language objective was to be able to describe applications of transformers in daily life using appropriate language. In the first task the student teachers used a diagram to guide students to discuss the structure and working principle of a transformer. For the second task, the student- teacher guided the students to deduce the transformer equation though step by step writing. The last task was through jigsaw method, the students were guided to discuss, write and present (read) the uses of transformers in daily life using complete sentences. Student teachers were instructed to write full sentences.

The third cycle lessons were also extracted from the third course content, which was about approaches in teaching and learning Physics. The student teachers in groups of five were supposed to prepare language supportive practical oriented lessons which were presented in 60 minutes each. Two of these were selected as sample lessons for this study. The first lesson presentation was about the phenomenon of reflection in curved mirrors. The specific Physics content objectives included: defining, given a ray diagram, the related terms like concave mirror, con, principal focus, radius of curvature, reflections, principal axis of the mirror, and principle focus pole of the mirror; to determine the position of images using graphical methods; and discuss the real applications of the curved mirrors. The language objectives were to write and pronounce well the key terms related to reflection in curved mirrors; describe the position of an image with the appropriate language using the prepositions between, behind, in-front-of, beyond, at, etc; and describe characteristics of images using the adjectives magnified, inverted, real, virtual, diminished etc. In the first task the student-teacher provided the students with the curved 
mirrors to manipulate and observe the characteristics of the image formed by them. Then, using ray diagrams the student- teacher guided the students to define various terms related to the phenomenon of reflection in curved mirrors. Later on, the students were guided to write sentences discussing the characteristics of the images formed by the curved mirrors using the adjectives real, virtual, inverted, diminished, magnified, etc. Moreover, using graphical method, the students were guided to determine image position when the objects were located at different positions. The teacher asked the students to describe position of the images using the prepositions behind, beyond, in-front-of, at, between etc. Finally the students, in a plenary discussion shared their experiences about the uses of the curved mirrors in real life, like shaving mirrors, driving mirrors, etc.

The second lesson presented in the third cycle was about Structure and Properties of Matter. The specific Physics content objectives included: - defining the term elasticity, using at least three examples, distinguish elastic from non-elastic materials, and investigate and demonstrate the relationship between tension and extension of loaded elastic materials appropriately (Hooke's law). The language objectives pointed out by the students teachers included: vocabulary development on the meaning of related vocabulary like extension, tension, elasticity, rubber band and spiral spring and their pronunciations, and discuss the Hooke's law. The student-teachers used buzz groups to demonstrate and guide their students to perform experiments to stretch elastic and non-elastic materials and discuss the observations and the differences. Then students were guided to mention examples of elastic materials from their real life experiences. Finally, the students, in groups of five, were guided to perform an experiment to determine the relationship between tension and extension.

\section{The Research Findings and Discussions}

\subsection{Exploring the characteristics of LSP integrates practical works}

The first objective of this study was to investigate the characteristics of LSP integrated practical works in relation to learning of science, English language proficiency skills, and development of pedagogy. Review of lesson plans prepared by the student-teachers, classroom observations, focus group discussions by the lecturers and interviews to the case students, the following are the features of LSP integrated practical works can be drawn: Interdisciplinary collaboration among teachers: The students were exposed to the mode which required them to collaborate with other 
teachers in other specializations, especially the English language teachers. The instructor needs to collaborate with English teachers to build his or her English language proficiency skills in relation to the science topics. The instructor may consult English texts and references like dictionaries for development of grammar and pronunciation skills. Aiming at multiple outcomes: The lessons aimed at multiple outcomes; language learning, physics learning and development of pedagogical-content-knowledge. The lessons had three types of objectives; content, language and pedagogy objectives. Lemke (1990) maintains that science lessons aim at learning how different phenomena and processes are expressed in scientific language.

Therefore, mastery of science involves learning how to talk, read and write about science. Defining the Key Terms related to the topic or practical work design: The lesson involved the studying the meaning of the vocabulary related to the key terms related to the topics, subtopics and experimental designs. This was done through giving the definitions or interpretation or translation of the terms. Translation (English-Swahili translation) was employed by the instructors especially when the students failed to capture the meaning of some English vocabularies through interpretation. Active engagement by students in reading, writing, practical activities and discussions: There was active involvement of the students in the lessons. The student-teachers were actively engaged in writing the LSP integrated practical oriented lesson plans, implementing the lessons, dong practical tasks and discussing the observations and findings of the practical activities. The students were involved in talking, writing and doing practical works. Students were involved in writing out the procedures, explaining the steps to others, telling the names and functions of the apparatus used, discuss the results of the experiments, and writing the report of the experiments. Language error correction: To curb the noted challenges, the lesson observers employed spontaneous correction strategy especially when common mistakes were committed by the students. For instance, the language expert would provide the students with ideal pronunciation and grammar deemed necessary. Similarly, the students were also spontaneously assisted by the physics experts especially when some scientific terms were wrongly conceptualized. By the end of the lessons, a short time spared for the language expert to clarify language issues in relation to the errors committed. In addition to that, the lessons also involved practicing reading skills using science based texts. For instance, they were provided with designs of some experiments, whereby they were supposed to read and comprehend the procedures of the experiments. Finally, the students were to practice grammar 
while developing the practical activities and discuss the ideas from the observations and the results of the practical works. The grammatical errors were corrected immediately, in the talking or writing tasks. Where necessary, the lessons included interpretations and translations of the key subject / topic vocabulary. Worth (2008) asserts that when students discuss about science with their colleagues and their teachers, they make meaning from their own thinking, listen to the ideas of others, they become aware of multiple perspectives and can evaluate other's and their own ideas.

Interviews were conducted with the case students immediately after each lesson. The interviews considered the things that learners enjoyed during the lesson, new vocabulary learned during the lesson, content learned from the lesson, methods that worked best for students, improvements for next lesson and language skills learned from the lesson. The interview guide is shown in appendix 2 . The following are interview responses by the learners. In general in all the lessons students reported to have enjoyed the emphasis of the lessons on the relationship between the theoretical Physics lessons and their applications in the real world through the use of real objects as teaching aids. Moreover, the student teachers enjoyed their participations in the lesson activities, strategic use of Kiswahili, and Swahili translations. Moreover, the students enjoyed student-presentations from their colleagues. The students reported to have learned about the relationship of the terms practical work, experiment and investigation, reflection by curves mirrors and their applications in real life, Elasticity and Hooke's law, working of a transformer and its applications in electrical circuits, determination of image position through graphical methods, how to construct a transformer, how to report an experimental work. Practical works integrated with sharing of experiences and ideas was reported to have helped the students to understand better the lesson. Group discussion method also worked best as it helped students share ideas with fellow students in order to grasp different concepts in the lesson. Observation method worked best because one could learn through more than one sense organ. The probing questions asked promptly helped the students to improve in thinking and speech/questions asked promptly. Moreover, the strategic use of Kiswahili in teaching and learning process gives a room for most students to actively participate in the lessons. 


\subsection{Adaptation of the student-teachers to the LSP integrated practical works}

The second objective of the research was to evaluate the adaptation of the student teachers to LSP integrated practical works and the effectiveness of the model to learning science, language proficiency skills, and development of Pedagogy. This was done through review of the students' lesson plans, classroom observations, focus group discussions by the lecturers, interviews to the case students and achievement tests. The review of the students' lesson plans and classroom observations show that the student-teachers were able to prepare and implement effective LSP oriented practical-based lessons. A Lesson plan excerpt from the first lesson in the third cycle of the study about Reflections in Curved Mirrors is shown in Figure 4.1.

\begin{tabular}{|l|l|l|l|l|}
\hline $\begin{array}{l}\text { New } \\
\text { Knowledge }\end{array}$ & $\begin{array}{l}\text { Time } \\
15\end{array}$ & $\begin{array}{l}\text { Teaching Activities } \\
\text { Mead the students to } \\
\text { write } 5 \text { sentences to } \\
\text { express nature of } \\
\text { images formed by } \\
\text { the curved mirrors }\end{array}$ & $\begin{array}{l}\text { Learning Activity } \\
\text { In pairs write 5 } \\
\text { thences to describe } \\
\text { formed by the curved } \\
\text { mirrors }\end{array}$ & $\begin{array}{l}\text { Assessment } \\
\text { Activity } \\
\text { the sentences are } \\
\text { correct }\end{array}$
\end{tabular}

Figure 4.1: A Lesson Plan Excerpt from the First Lesson in the Third Cycle of the Study about Reflections in Curved Mirrors (Field Data, 2018)

Through the study, the case student-teachers reported to have learned the meaning of a number of vocabularies related to science content and pedagogy. The students also were given a chance to evaluate the efficiency of the lessons by providing their suggestions for improvement. They suggested that teachers should emphasize pronunciations through modeling. They also suggested that student presentations should be promoted as they increase students' confidence in learning. In addition, they argued that discussions and reading practices in classrooms context should be encouraged to improve both reading and pronunciation skills. They argued that discussions promote the students' reasoning ability and strengthen interactions. Furthermore, they preferred that, teachers should always correct the learners just in case of mistakes or errors and encourage slow learners participate effectively in teaching and learning process. The students also noted that there was a problem of time management in lesson development, particularly in the first lesson. The teacher should plan a few and critical activities relevant to the learning as usually practical tasks are time consuming. It is wise to select only important activities found more relevant for the lesson. The case students were also asked to state any 
language skills they perceived to have learned during the lessons. They reported to have learned correct pronunciation of many words, grammatical aspects in construction of sentences, speaking skills through presentations in the classroom, learning of the key subject vocabulary, use of language which is appropriate to the level of students, use of simple sentences in both written and spoken English. They also appreciated that the strategic use of Kiswahili facilitated their learning of various concepts.

The analysis of the post-test scores for the case study students was done to determine whether or not there was significant increase in performance from the pre-test to the post-test. Initially descriptive section of the items and classroom observation of the case students had shown that the student teacher's faced difficulty in expressing themselves. Areas in which errors were noted included: Omitting of punctuation marks and use of inappropriate punctuation marks, for example '...interactive method this is the sharing of.....'; lack of subject - verb agreement especially for third person singular, for example '...this allow...', It involve use of...'; misspellings, examples '.......it is less costfull......', '.... by using demostration teaching method....'; Lack of plural markers, for example '....method of teaching physics include....' and '..... the following are the reason ......'. Some high performing students appeared to use too long sentences without punctuation marks leading to confusion of intended idea(s). e.g. '...Experimentation method is better because; involve the use of all senses ie. ear, skin, tongue and mouth which help student to understand better, also this method help teacher to easily explain some abstracts complex ideas, also by using experiment method it is easier student to memorize as they forget ...'

Table 4.1 indicates the distribution of both pre- and post-test scores for case students. The post-test performance was high for all the case students with higher gain for the lower performing students. 
Table 4.1: Distribution of pre- and post-test scores of the case students

\begin{tabular}{|c|c|c|c|c|c|c|c|}
\hline S/no & Case & $\begin{array}{l}\text { Student } \\
\text { Identity }\end{array}$ & Sex & Pre-test & $\begin{array}{l}\text { Post-Test } \\
\mathrm{x} / \mathbf{1 0 0})\end{array}$ & Gain & Status \\
\hline 1 & CS 1 & & $\mathrm{M}$ & 39.5 & 74.1 & +34.6 & LP \\
\hline 2 & $\mathrm{CS} 2$ & & $\mathrm{M}$ & 53 & 66.6 & +13.6 & LP \\
\hline 3 & CS3 & & $\mathrm{F}$ & 69.5 & 82.2 & +12.7 & LP \\
\hline 4 & CS4 & & $\mathrm{F}$ & 77.5 & 88.5 & +11 & LP \\
\hline 5 & CS5 & & $\mathrm{F}$ & 81 & 90.5 & +9.5 & HP \\
\hline 6 & CS6 & & $\mathrm{F}$ & 85 & 89 & +4 & HP \\
\hline 7 & CS7 & & M & 89 & 93.5 & +4.5 & HP \\
\hline 8 & CS8 & & $\mathrm{M}$ & 91 & 95 & +4 & HP \\
\hline
\end{tabular}

Key: LP - Low Performance, HP - High Performance, CS - case student.

Source: Pre-test (2018)

Another analysis was done to compare the pretest and posttest results of all the student-teachers on the scale of $100 \%$, using the repeated measures $t$ test, with confidence interval of $95 \%$ The repeated measures t-test has shown that there was a statistically significant increase of the means scores from pre-test to the post-test. The number of students who attended both tests was 55 . Pretest mean was 67.9 and the posttest mean was 80.165 . The standard deviation which is the measure of variability in scores among students show that there was a much decrease of the variation of scores among the student teachers. The paired sample statistics are shown in Table 4.2 . 
Table 4.2: Paired Sample Statistics

\begin{tabular}{llllll}
\hline & & Mean & N & Std. Deviation & Std. Error Mean \\
\hline Pair & PRE-TEST & 67.90 & 55 & 24.9493 & 3.3642 \\
& & & & & \\
& POST-TEST & 80.16 & 55 & 6.6153 & 0.8920 \\
& & & & \\
\hline
\end{tabular}

The number of students $\mathrm{N}=55(M=67.9, S D=24.9)$ and post-test $[M=80.2, S D=6.6$; $t(54)=-3.972, p=0.000]$. The eta squared statistic (0.226). Hence, there was a significant rise in the mean scores from 67.9 to 80.2 . The magnitude of the difference in the means was very large (eta squared $=0.226$ ), indicating a very large effect size. The paired samples t-test results are shown in Table 4.3 .

\section{Table 4.3: Paired Samples Test}

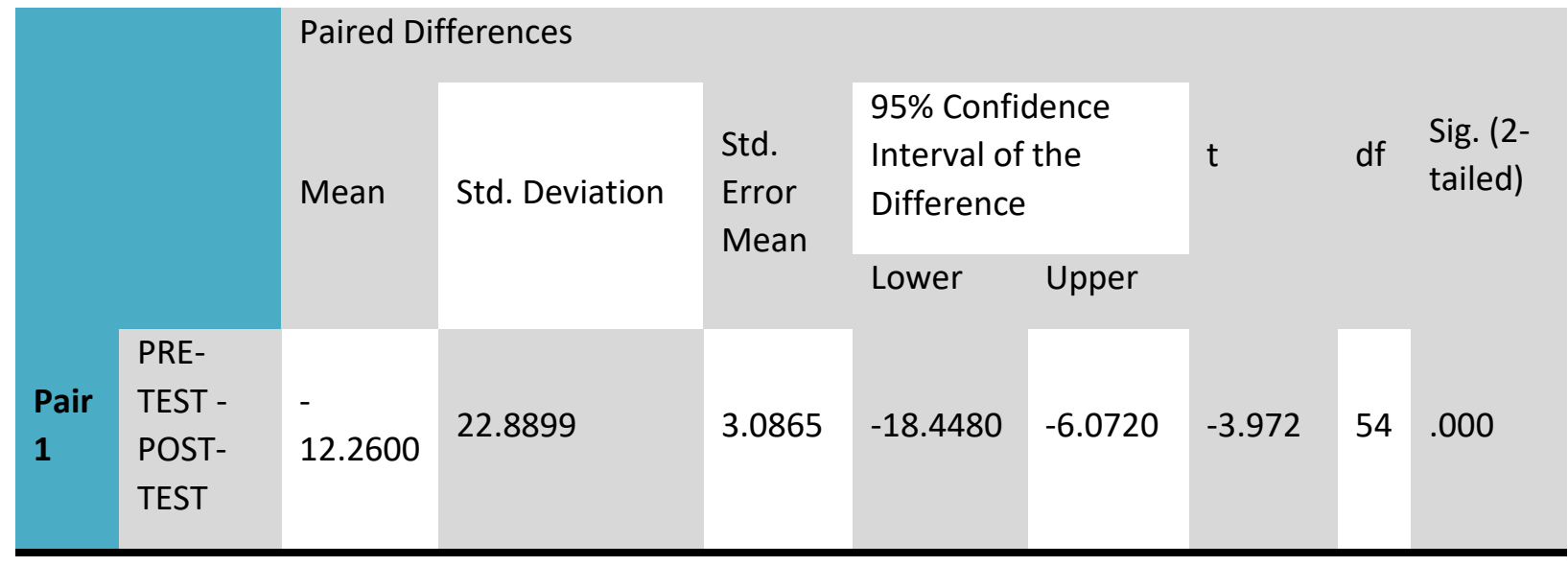

Generally, LSP integrated practical works facilitated much improvement of language skills among the student- teachers. However, this microteaching with the second year university student-teachers whose language proficiency was more developed compared to the target students in secondary schools. The little benefit shown is likely to be magnified when working with the learners with lower language proficiency in the secondary schools. Abrahams and Millar (2008) highlights that practical work can be significantly improved if teachers and science book writers are aware that, the practical oriented lessons need to make connections between the domains of observables (objects, events and phenomena) and the domain of ideas. A similar 
study was conducted by Callahan, Sampson and Rivale ( 2019 ) on activating bilingual English language learners' strengths in Science using the pedagogy of Argument Driven Inquiry ADI). The ADI was done through eight instructional stages which include task identification and guiding question, method design and data collection, data analysis and initial argument development, argumentation, explicit and reflective discussion, investigative report writing, double-blind peer review, and report revision and submission. In all the eight steps the students produced spoken and written accounts of their experience. Hence, through eight steps the students engaged with oral and written language, integrated with laboratory experiences. The ADI instructional model was reported to be useful for providing English language learners with opportunities to participate in the practices of science while strengthening their English and scientific literacy skills.

\section{Supporting English Language Learners}

After implementation of the LSP practical based lessons the lecturers held a reflection meeting to evaluate the study. The following challenges were noted: Firstly, most of the students faced the challenges of writing the language objectives as they were used to traditional way of writing their lesson plans which did not include such kind of objectives. Language supportive practical lessons require more text books and reference materials with language supportive qualities. Therefore, the implementation of LSP approach in secondary schools may be limited by the likely current shortage of reading and practical materials which are language supportive. They also highlighted that LSP lessons require careful planning and more time for organizing the teaching and learning activities. This integrations of LSP with practical works is more demanding than practical works which that simply require students to observe and remember the observable features of an event or process (Abrahams \& Millar (2008). They also require searching for suitable materials and reviewing of the key vocabulary before the execution of LSP lesson. Finding time for LSP facilitators' meeting has been very challenging due to the fact the members came from different colleges and were being occupied by different university engagements. However, encompassed with high degree of commitment, the study was conducted successfully. Callahan, Sampson and Rivale ( 2019 ) acknowledge that, if poorly implemented with little attention to classroom social dynamics, even the LSP integrated practical works might lead to exclusion of science students who are English language learners in the science 
classroom. What is important for science teachers is to constantly questions and refine instructional practices.

\section{Conclusions}

LSP practical based lessons shared the following characteristics:- As the lessons aim at multiple outcomes; language learning, science learning and development of pedagogy there is a need for the science teacher to collaborate with the English teachers to prepare learning experiences which aim at language learning and science content learning. The LSP integrated practical oriented lessons need to include interpretations and translations of the key subject / topic vocabulary and involvement in reading guides to promote reading skills. Based on the study findings, it can be concluded that the student teachers were able to adapt well to the LSP integrated practical works as the lessons they planned and executed reflected the LSP features and were effective improving science learning, development of English language skills and improvement in pedagogy. These findings are similar to that observed by Milligana, Clegg and Tikly (2016) that language supportive learning can improve language as well as other subjects across the curriculum.

This kind of research may be scaled up to involve pre-service teachers, in-service teachers and more secondary schools. Furthermore, the language supportive pedagogy can be included in the teacher education institutions and secondary school curriculum. The study suggests alternative bilingual classrooms, through the use Kiswahili strategically in a classroom where English language dominates as the language of instruction. Thus, the policy makers may formulate the guidelines for the bilingual classrooms in secondary schools, as already the policy allows the use of both English and Kiswahili in secondary schools.

\section{References}

Abrahams, I. \& Millar, R. (2008). Does Practical Work Really Work? A study of the effectiveness of practical work as a teaching and learning method in school science. International Journal of Science Education 30 (14) 1945-1969.

Callahan, R.M., Sampson, V. \& Rivale, V. (2019). Activating bilingual English Language learners' strengths in science: The pedagogy of argument driven inquiry (ADI). In L.C. De Oliveira, K.M. Obenchain, R.H. Kenney, A.W. Oliveira (Eds). Teaching the content 
areas to English language learners in secondary schools: English language arts, mathematics, science, and social Studies (pp.183-198). West Lafayette: Springer Nature.

Cho, S. \& McDonnough, J. T. (2009). Meeting the needs of high school science teachers in English language learner instruction. Journal of Science Teacher Education, 20 (4) 385402.

De Oliveira, L.C., Obenchain,K.M., Kenney,R.H.\& Oliveira, A.W. (2019). Languagecontent integration across school subjects: Approaches to teaching English language learners. In L.C. De Oliveira, K.M. Obenchain, R.H. Kenney, A.W. Oliveira (Eds). Teaching the content areas to English language learners in secondary schools: English language arts, mathematics, science, and social studies (pp.1-20). West Lafayette: Springer Nature.

Exploratorium (2015). Developing language in the context of science: A View from the Institute for Inquiry® downloaded from https://www.exploratorium.edu/sites/ default/files/pdfs/ifi/DevelopingLanguageinthe ContextofScience.pdf on $4^{\text {th }}$ April, 2020.

Heugh, K. (2003). Multilingual education policy in South Africa constrained by theoretical and historical disconnections. Annual Review of Applied Linguistics 33, 215-237

Hinneh, J. T. (2017) Attitude towards practical work and students' achievement in Biology: A case of a private senior secondary school in Gaborone, Botswana. Journal of Mathematics 13 (4) 6-11.

Hodson, D. (1998). Mini-special Issue: taking practical work beyond the laboratory. International Journal of Science Education, 20 (6) 629-633.

Jokiranta, K. (2014) Effectiveness of practical work in science education. Recent Research Studies, 1 (3) 32-60.

Kibga, E. Y. (2013). Strengthening science practical work for secondary school teachers in Tanzania through development of in-service training materials. Unpublished PhD Thesis: The University of Dar es Salaam 
Kim, M. \& Chin, C.(2011). Pre-service teachers' views on practical work with inquiry orientation in textbook oriented science classrooms, International Journal of Environmental and Science Education, 6 (1) 23-37.

Language Supportive Textbooks and Teaching (LSTT) (2014) Strengthening secondary education in practice: Language supportive textbooks and teaching in Tanzania. Pilot Study Report

Leedy, P.D. \& Ormrod, J.E (2015). Practical research: Planning and design. $11^{\text {th }}$ ed. Harlow: Pearson Education Limited Publishers.

Lemke, J. L. (1990). Talking science: Language, learning, and values. Norwood,N.J.: Ablex.

Lunetta, V.N. (1998). The school science laboratory: Historical perspectives and contexts for contemporary teaching. In K. Tobin \& B. Fraser (Eds.), International Handbook of Science Education (Part 1, pp. 249-262). Dordrecht: Kluwer.

Millar R. (2004). The role of practical work in the teaching and learning of science. A paper prepared for the committee of High School Science Laboratories: Role and Vision. Washington, DC: National Academy of Sciences.

Millar, R., Le Mare'chal, J. \& Tiberghien, A. (1999). Mapping the domain: Varieties of practical work. In J. Leah \& A. Chr. Paulsen (Eds.). Practical Work in Science Education: Recent Research Studies.(pp.33-59). Denmark: University Press.

Milligana, L.O., Clegg, J.\& Tikly, L. (2016). Exploring the potential for language supportive learning in English medium instruction: a Rwandan case study. Comparative Education $52(3), 328-342$.

Mwinsheikhe, H.M. (2009). Spare no means: Battling with the English/Kiswahili dilemma in Tanzanian secondary school classrooms. In B. Brock-Utne \& Skattum. (Eds) Language and Education in Africa: A comparative and transdisciplinary analysis. (pp. 223-234). Bristol: Symposium Books.

Nomlomo, V.S. (2007).Science teaching and learning through the medium of English and isiXhosa: A comparative study of two primary schools in the Western Cape. Ph.D. Dissertation. Cape Town: University of Western Cape. 
Nomlomo, V. \& Vuzo, M. (2014). Language transition and access to education: Experiences from Tanzania and South Africa. International Journal of Educational Studies.1 (2) 73 82.

Nutta,J.W., Bautista, N.U. \& Butter, M.B. (2011). Teaching science to English language learners. New York: Taylor \& Francis

Osaki, K., Hosea, K. \& Ottevanger, W. (2004). Reforming science and mathematics educations in sub-Saharan Africa. Dar es Salaam: TEAMS project.

Qorro, M.A.S. (2009). Parents' and policy makers' insistence o foreign languages as media of education in Africa: Restricting access to quality education - for whose benefit? In B. Brock-Utne \& I..Skattum. Language and Education in Africa: A Comparative and Transdisciplinary Analysis (pp.57-82). Bristol: Symposium Books

Pando, M. \& Aguirre-Muñoz, Z. (2019). Engaging English Language Learners in Model-Based Science Instruction. In L.C. De Oliveira, K.M. Obenchain, R.H Kenney, A.W. Oliveira (Eds). Teaching the content areas to English language. learners in secondary schools: English language arts, mathematics, science, and social studies (pp.215-229). West Lafayette: Springer Nature.

Piaget, J. (1973). To understand is to invent: The future of education. New York: Grossman Publishers.

Rubagumya C.M., Afitska O, Clegg J. \& Kiliku P. (2011). A three-tier citizenship: can the state in Tanzania guarantee linguistic human rights? International Journal of Educational Development 31 (1) 78-85.

Sanders, M. E. \& Binerup, K. (2000). Integrating technology education across the curriculum. Reaton, VA: A monograph of the International Technology Teachers

Sharpe, R. M. (2012). Secondary school students' attitudes to practical work in school Science. Ph.D. Dissertation, University of York.

Thomson, N. (2012). Language teaching strategies and techniques used to support students' learning in a language other than their mother tongue. London: International Baccalaureate Organization 
URT (2014). Education and training policy 2014. Dar es Salaam: Tanzania Institute of Education.

Vygotsky, L. (1978). Mind in society: The development of higher psychological processes. Cambridge, MA: Harvard University Press.

Watson, R.(2000).The role of practical work. In M. Monk \& J. Osborne (Eds.) Good practices in science teaching. What research has to say? (Pp.57-71).Open University Press.

White, R.T. (1996).The link between the laboratory and learning. International Journal of Science Education. 18 (7) 761- 774.

Worth, K. (2008). Science talk and science writing: A view from the classroom. A presentation given at the Literacy Institute 2008, National Geographic School Publishing and Literacy Achievement Research Center.

Yin, R.K. (2018). Case study research applications: Design and methods. $6^{\text {th }}$ ed. London: Sage publications

Zehler, A. (1994). Working with English language learners: Strategies for elementary and middle school teachers. NCBE Program Information Guide, No. 19. Retrieved October 23, 2019, from www.ncela.gwu.edu/pubs/pigs/pig19.htm. 